\title{
Nicotine induces TIPE2 upregulation and Stat 3 phosphorylation contributes to cholinergic anti-inflammatory effect
}

\author{
HUA XIU SUI ${ }^{1,2^{*}}$, SHI ZHONG KE ${ }^{1 *}$, DAN DAN XU ${ }^{1}$, NAN NAN LU ${ }^{1}$, YI NAN WANG ${ }^{1}$, \\ YUE HUA ZHANG ${ }^{1}$ and FENG GUANG GAO ${ }^{1,3}$ \\ ${ }^{1}$ Department of Immunology, Basic Medicine Science, Medical College, Xiamen University,

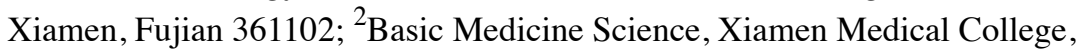 \\ Xiamen, Fujian 361023; ${ }^{3}$ State Key Laboratory of Oncogenes and Related Genes, \\ Shang Hai Jiao Tong University, Shanghai 200032, P.R. China
}

Received May 22, 2017; Accepted July 24, 2017

DOI: $10.3892 / \mathrm{ijo} .2017 .4080$

\begin{abstract}
Cholinergic anti-inflammatory pathway has therapeutic effect on inflammation-associated diseases. However, the exact mechanism of nicotine-mediated anti-inflammatory effect is still unclear. TIPE2, a new member of tumor necrosis factor$\alpha$-induced protein- 8 family, is a negative regulator of immune homeostasis. However, the roles of TIPE2 in cholinergic antiinflammatory effect are still uncertain. Here, we demonstrated that nicotine exerts its anti-inflammatory effect by TIPE2 upregulation and phosphorylated stat 3 mediated the inhibition of NF- $\kappa \mathrm{B}$ activation, which was supported by the following evidence: firstly, both nicotine and TIPE2 inhibit pro-inflammatory cytokine release via NF- $\mathrm{B}$ inactivation. Secondly, nicotine upregulates TIPE2 expression via $\alpha 7$ nicotinic acetylcholine receptor. Moreover, the enhancement of stat 3 phosphorylation and decrease of LPS-induced p65 translocation were achieved by nicotine treatment. Importantly, nicotine treatment augments the interaction of phosphorylated stat 3 and p65, indicating that the inhibitory effect of nicotine on NF- $\mathrm{B}$ activation was mediated with protein-protein interactions. Hence, this study revealed that TIPE2 upregulation and stat 3 phosphorylation contribute to nicotine-mediated anti-inflammation effect, indicating that TIPE2 and stat 3 might be potential molecules for dealing with inflammation-associated diseases.
\end{abstract}

Correspondence to: Professor Feng Guang Gao, Department of Immunology, Basic Medicine Science, Medical College, Xiamen University, Xiamen, Fujian 361102, P.R. China

E-mail: gfengguang@xmu.edu.cn

${ }^{*}$ Contributed equally

Key words: nicotine, tumor necrosis factor- $\alpha$ induced protein-8like 2, NF- $\kappa \mathrm{B}$, Stat3

\section{Introduction}

Inflammation is a fundamental physiological process for survival. However, excessive expression of pro-inflammatory cytokines can cause a lethal systemic inflammation $(1,2)$. 'Cholinergic anti-inflammatory pathway' is well known for its role in autonomic nervous system (3). Nicotine, a selective cholinergic agonist, inhibits pro-inflammatory cytokine release in $\alpha 7$ nicotinic acetylcholine receptor ( $\alpha 7 \mathrm{nAchR})$-dependent manner (4). Substantial evidence points to a critical role of nicotine in preventing nuclear translocation of the $\mathrm{NF}-\kappa \mathrm{B}$ complex $(5,6)$, which demonstrated the inhibitory effects of nicotine on $\mathrm{NF}-\kappa \mathrm{B}$ activity $(7,8)$. Although therapeutic use of nicotine has been documented in depression, Tourette's syndrome, Parkinson's disease, Crohn's disease and ulcerative colitis (9-11), the mechanisms of cholinergic anti-inflammation are still uncertain.

Stat 3 is critical for physiological regulation of cell differentiation, growth, apoptosis and immune response $(12,13)$. Mice with stat 3 knockout in macrophages and neutrophils had enhanced inflammatory activity (14). Deletion of stat 3 results in myeloid cell abnormalities and causes Crohn's disease-like pathogenesis (15), indicating that stat 3 is a potential negative regulator of inflammation. Nicotine exerts its anti-inflammatory effect via Jak 2 and Stat 3 signaling $(15,16)$, however, little is known about the role of stat 3 phosphorylation in nicotineinhibited $\mathrm{NF}-\kappa \mathrm{B}$ activation.

Tumor necrosis factor- $\alpha$ induced protein-8-like 2 (TIPE2), a member of tumor necrosis factor- $\alpha$-induced protein- 8 family, inhibited TCR-mediated T cell activation, NF- $\kappa$ B activation (17), and is involved in the pathogenesis of stroke (18). However, up to now, the role of TIPE2 in cholinergic antiinflammatory pathway is still unknown, which is definitely important for controlling a variety of inflammation-associated diseases.

Here we provide evidence that TIPE2 and stat 3 mediated the anti-inflammation effect of nicotine, which is ultimately involved in the inhibition of p65 activity. Firstly, it was supported by the fact that both nicotine and TIPE2 inhibit 
pro-inflammatory cytokine release with $\mathrm{NF}-\kappa \mathrm{B}$ inactivation. Secondly, nicotine upregulates TIPE2 expression via Erk1/2 and PI3K/Akt pathways. Moreover, the treatment with nicotine increase stat 3 phosphorylation and inhibits nuclear translocation of p65. Importantly, co-immunoprecipitation assay reveals that the treatment with nicotine augments the interaction of phosphorylated stat 3 and $\mathrm{p} 65$. Hence, this study reveals that TIPE2 upregulation and stat 3 phosphorylation might contribute to nicotine-mediated anti-inflammation effect, indicating that TIPE2 and stat 3 might be potential molecules for dealing with inflammation-associated diseases.

\section{Materials and methods}

Reagents. Nicotine, $\alpha$-bungarotoxin and lipopolysaccharides (LPS) were purchased from Sigma-Aldrich (MO, USA). PMA and ionomycin were purchased from Beyotime (Shanghai, China). Recombinant murine M-CSF and IL-4 were obtained from R\&D (Minneapolis, MN, USA). Fetal bovine serum was obtained from Hyclone (Logan, UT, USA). Brefeldin A Solution, Fluorescene conjugated antibodies and mouse IL-12/IL-4 ELISA kits were from eBioscience (San Diego, CA, USA). NE-PER Nuclear and Cytoplasmic Extraction reagents were purchased from Pierce (Rockford, IL, USA). AG490, LY294002 and Wortmannin were purchased from Cayman Chemical (Ann Arbor, MI, USA). U0126, PD98059, antibodies to total or phosphorylated kinases, $\beta$-actin and histone $\mathrm{H} 3$ were purchased from Cell Signaling (Beverly, MA, USA). TIPE2 antibody was purchased from Abnova (Taipei, Taiwan). Protein A/G Plus-Agarose was purchased from Santa Cruz Biotechnology (CA, USA). SYBR ${ }^{\circledR}$ Premix Ex $\mathrm{Taq}^{\mathrm{TM}}$, TRIzol and Prime-Script Reverse Transcriptase were purchased from Takara (Dalian, China).

Animals. Pathogen-free Balb/c mice (female, 3-week-old) were purchased from Shanghai Laboratory Animal Center of the Chinese Academy of Sciences (China) and kept at the Animal Center of Xiamen University. All animal studies were approved by the Review Board of Medical College of Xiamen University. Mice were subcutaneously injected with nicotine $(0.5 \mu \mathrm{g} / 10 \mathrm{~g}$, twice per day) for 9 days. Control mice were subcutaneously injected with PBS. At the end of treatment, mice were sacrificed and further investigation was performed.

Cell lines. Murine macrophage cell lines Raw 264.7 cells were obtained from Shanghai Cell Bank (Shanghai, China). Cells were cultured in DMEM medium with $10 \%$ fetal bovine serum at $37^{\circ} \mathrm{C}$ in $5 \% \mathrm{CO}_{2}$. Cells were synchronized by serum starvation for at least $12 \mathrm{~h}$ before the treatment of nicotine or LPS.

TIPE2 transfection. TIPE2 overexpressed Raw 264.7 cells were established according to the method described previously (17). Briefly, 6x10 5 cells/well were seeded in 6-well plates and transfected with pcDNA3.1-TIPE2 constructs and empty vector using PEI (Polyplus, AFAQ) according to the manufacturer's instructions. TIPE2 overexpressed cells were selected in $500 \mu \mathrm{g} / \mathrm{ml} \mathrm{G} 418$ condition and confirmed by RT-PCR and western blotting, respectively.
Bone marrow-derived murine macrophage. Bone marrowderived macrophage was prepared as previous description (19). Briefly, bone marrow mononuclear cells were prepared from bone marrow suspensions by depletion of red cells and then cultured at a density of $1 \times 10^{6}$ cells $/ \mathrm{ml}$ in RPMI-1640 medium with $10 \mathrm{ng} / \mathrm{ml}$ of M-CSF and $1 \mathrm{ng} / \mathrm{ml}$ of IL-4. Non-adherent cells were gently washed out with PBS on day 4 of culture; the remaining loosely adherent clusters were used as macrophages. To explore the effect of nicotine on $\alpha 7 \mathrm{nAchR}$ and TIPE2 expressions, macrophage was conferred 0.1-10 $\mu \mathrm{M}$ nicotine 24-h stimulation. To determine the effect of nicotine on TNF- $\alpha$ expression, macrophage pretreated with $1 \mu \mathrm{g} / \mathrm{ml} \alpha$-bungarotoxin prior to nicotine treatment was further conferred $100 \mathrm{ng} / \mathrm{ml}$ LPS stimulation.

ELISA. To investigate the effect of nicotine on cytokine secretion, purified splenic $\mathrm{T}$ cells from nicotine-administered mice were cultured at a density of $2 \times 10^{5} /$ well in U-bottom 96-well plates in the presence of PMA $(50 \mathrm{ng} / \mathrm{ml})$ and ionomycin $(1 \mu \mathrm{M})$ for $12 \mathrm{~h}$. Culture supernatants were collected and the concentrations of IL-12, IL-4 were determined by ELISA (21).

Flow cytometric measurement. Expressions of cell surface molecules and pro-inflammatory cytokine release were determined by flow cytometry according to the methods described previously (20).

Cytoplasmic and nuclear extracts isolation. Cytoplasmic and nuclear extract was prepared as previously described (21). Briefly, TIPE2 overexpressed and control Raw 264.7 cells were pretreated with nicotine $(1 \mu \mathrm{M})$ prior to $100 \mathrm{ng} / \mathrm{ml} \mathrm{LPS}$ 6-h stimulation. Then, the cells were collected and suspended in ice-cold CER buffer (cytoplasmic extraction reagent), vortexed for $10 \mathrm{~min}$ and ice-cold CER was added. The cytosolic fraction (supernatant) was separated by centrifugation $\left(16,000 \mathrm{x} \mathrm{g}, 5 \mathrm{~min}, 4^{\circ} \mathrm{C}\right)$ and the nuclear protein was separated by incubating insoluble fraction with ice-cold NER (nuclear extraction reagent) for $40 \mathrm{~min}$ and centrifuged at $16,000 \mathrm{x} \mathrm{g}$ for $10 \mathrm{~min}, 4^{\circ} \mathrm{C}$. Protein concentration was estimated using the Bio-Rad protein assay reagent and an equal amount of proteins per sample of nuclear extract was further analyzed by western blotting.

Western blotting. Proteins were obtained in lysis buffer as previously described (22). Proteins were loaded onto SDS-PAGE gels for electrophoresis and transferred to PVDF membranes. After blocking in 5\% fat-free milk in TBST for $1.5 \mathrm{~h}$, the membranes were incubated with primary antibodies at $4^{\circ} \mathrm{C}$ overnight. After that, the membranes were incubated with corresponding HRP-conjugated secondary antibodies at room temperature for $1.5 \mathrm{~h}$. After washing six times with TBST (for $10 \mathrm{~min}$ each), bound antibodies were visualized using chemiluminescence ECL. $\beta$-actin or histone H3 were used as loading control.

Reverse transcriptase polymerase chain reaction. TIPE2 overexpressed Raw 264.7 and control cells were seeded in 6 -well plate $\left(1 \times 10^{5}\right.$ cells/well $)$ and total RNA was isolated using TRIzol and reverse-transcription was performed according to the standard procedure (20). Subsequent PCR amplification was performed using $2 \mu \mathrm{g}$ cDNA in the following 
condition: $95^{\circ} \mathrm{C}$ for $30 \mathrm{sec}, 35$ cycles of $\left(95^{\circ} \mathrm{C}\right.$ for $5 \mathrm{sec}, 58^{\circ} \mathrm{C}$ for $30 \mathrm{sec}$, and $72^{\circ} \mathrm{C}$ for $30 \mathrm{sec}$ ). $\beta$-actin was used as internal control. PCR products were run on $2 \%$ agarose gels and analyzed under ultraviolet (UV) light after ethidium bromide staining. $\beta$-actin: sense, 5'-ACCGTGGAGAAGAGC TACGA3'; antisense, 5'-GTACTTGCGCTCAGAAGGAG-3'. TIPE2 sense, 5'-CACCGCAATGGCTCCTTT-3'; antisense, 5'-CACCAACTCTAGCAGCACATC-3'.

Real-time PCR. Total RNA was extracted from mouse spleen and thymus according to the manufacturer's instructions (17). Reverse transcription was performed with oligo dT primers. Real-time PCR was carried out in Applied Biosystems 7500 system with Power SYBR Green PCR Master Mix (Applied Biosystems). Relative TIPE2 expression was determined with $\beta$-actin as the control.

Immunoprecipitation. Immunoprecipitation was performed as previously described (23). Briefly, Raw 264.7 cells pretreated with nicotine $(1 \mu \mathrm{M})$ prior to $100 \mathrm{ng} / \mathrm{ml}$ LPS stimulation were harvested and lysed in RIPA buffer (PBS containing $0.1 \%$ SDS, $0.5 \%$ sodium deoxycholate, $1 \%$ Nonidet P-40, $1 \mathrm{mM}$ sodium orthovanadate, $1 \mathrm{mM}$ PMSF and $3 \%$ protease inhibitor cocktail). These lysates were then pre-cleared by incubation with $20 \mu \mathrm{l} / \mathrm{ml}$ Protein $\mathrm{A} / \mathrm{G}$ agarose beads for $1 \mathrm{~h}$ at $4^{\circ} \mathrm{C}$. After brief centrifugation, the supernatant was added to the indicated primary antibody or control IgG in RIPA buffer overnight at $4^{\circ} \mathrm{C}$, followed by the addition of $20 \mu \mathrm{l} / \mathrm{ml}$ Protein $\mathrm{A} / \mathrm{G}$ agarose beads. Immunoprecipitates were washed in RIPA buffer, re-suspended in SDS sample buffer, boiled for $5 \mathrm{~min}$ and analysed by SDS/PAGE. Proteins were electrophoretically transferred to PVDF membranes and subjected to western blot analysis using the indicated antibodies.

Statistical analysis. Each experiment was repeated at least 3 times and confirmed that similar data were obtained. All data were presented as mean with standard error means. Statistical significance was tested using Student's t-test, one-way ANOVA with post Newman-Keuls test. Statistical differences were considered to be significant at $\mathrm{p}<0.05$.

\section{Results}

a7 $n A C h R$ is involved in nicotine-mediated inhibitory effect on inflammation. Although $\alpha 7 \mathrm{nAChR}$ is constitutive expressed on both DCs and monocytes, the roles of $\alpha 7$ $\mathrm{nAChR}$ in nicotine-mediated anti-inflammation are still uncertain. Toward this end, Balb/c mice were subcutaneously administered with nicotine and pro-inflammatory cytokines was determined. A statistically significant reduction in LPS inducing pro-inflammatory cytokines of TNF- $\alpha$, IL-4, IL-12 and IL-2 occurred in both splenic CD4 ${ }^{+}$ T cells (Fig. 1A and B). Subsequently, we tested if such nicotine treatment affects $\alpha 7 \mathrm{nAChR}$ expression. To this end, bone marrow-derived macrophage was treated with nicotine $\left(10^{-5}-10^{-7} \mathrm{~mol} / \mathrm{l}\right)$ and $\alpha 7 \mathrm{nAChR}$ expression was determined. Importantly, a clear upregulation of $\alpha 7 \mathrm{nAChR}$ was achieved by the treatment with nicotine (Fig. 1C), indicating that $\alpha 7$ $\mathrm{nAChR}$ is involved in nicotine-mediated anti-inflammation effect. To test this hypothesis, we pre-incubated macrophage
A
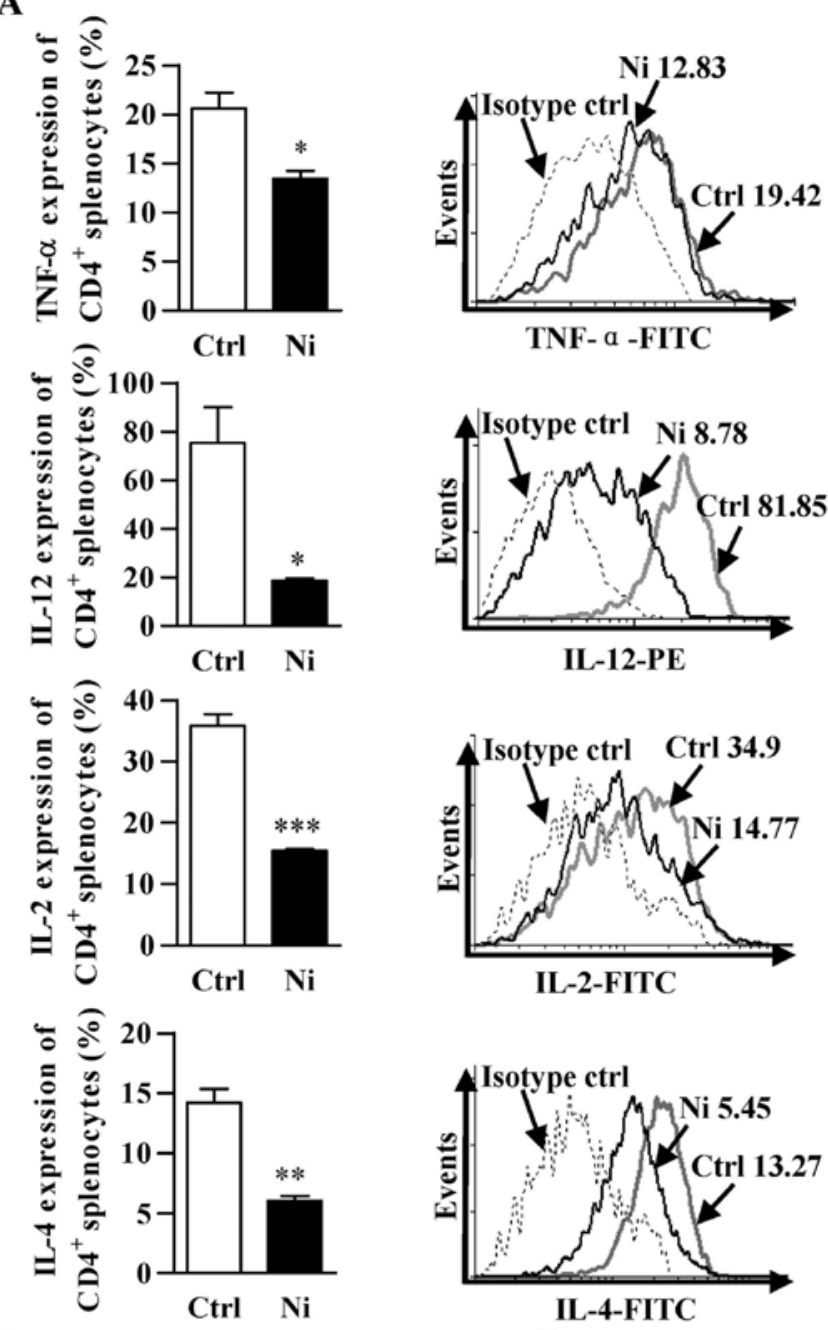

B

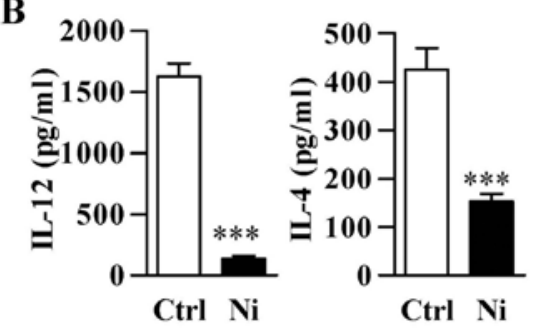

D
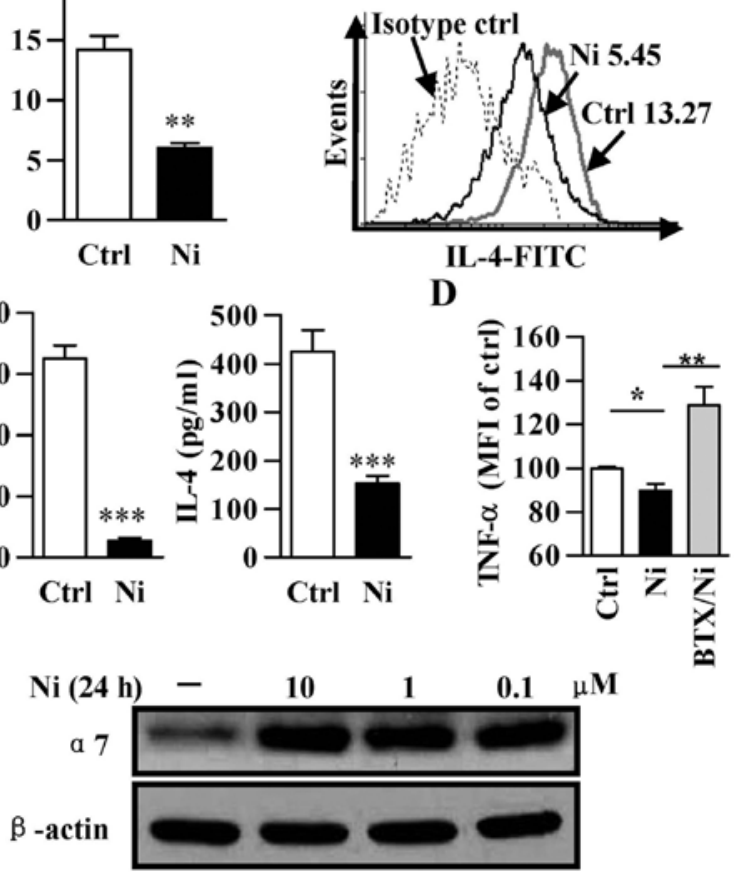

Figure 1. Nicotine treatment inhibits pro-inflammatory cytokine production. Balb/c mice were subcutaneously injected with nicotine $(0.5 \mu \mathrm{g} / 10 \mathrm{~g}$, twice per day) for 9 days. Then, splenic T cells were stimulated with PMA $(50 \mathrm{ng} / \mathrm{ml})$, ionomycin $(1 \mu \mathrm{M})$ and LPS $(100 \mathrm{ng} / \mathrm{ml})$ for $6 \mathrm{~h}$ and pro-inflammatory cytokines were determined by flow cytometry (A) and ELISA (B) respectively. Numbers in (A) represent mean fluorescence intensity (MFI) and positive cell percentage in each gated area. Murine macrophages derived from bone marrow were treated with nicotine for $24 \mathrm{~h}$ and $\alpha 7 \mathrm{nAchR}$ expression was determined by western blotting (C). Murine macrophage pretreated with $1 \mu \mathrm{g} / \mathrm{ml} \alpha$-bungarotoxin prior to nicotine $(1 \mu \mathrm{M})$ stimulation were further conferred LPS treatment $(100 \mathrm{ng} / \mathrm{ml})$ and TNF- $\alpha$ expression was determined by flow cytometry (D). Data are shown as mean \pm SEM, $n=3$, ${ }^{*} \mathrm{p}<0.05,{ }^{* *} \mathrm{p}<0.01,{ }^{* * *} \mathrm{p}<0.001$, Student's t-test or one-way ANOVA with post Newman-Keuls test. A representative out of three independent experiments is shown. Ni, nicotine; BTX, $\alpha$-bungarotoxin. 
A

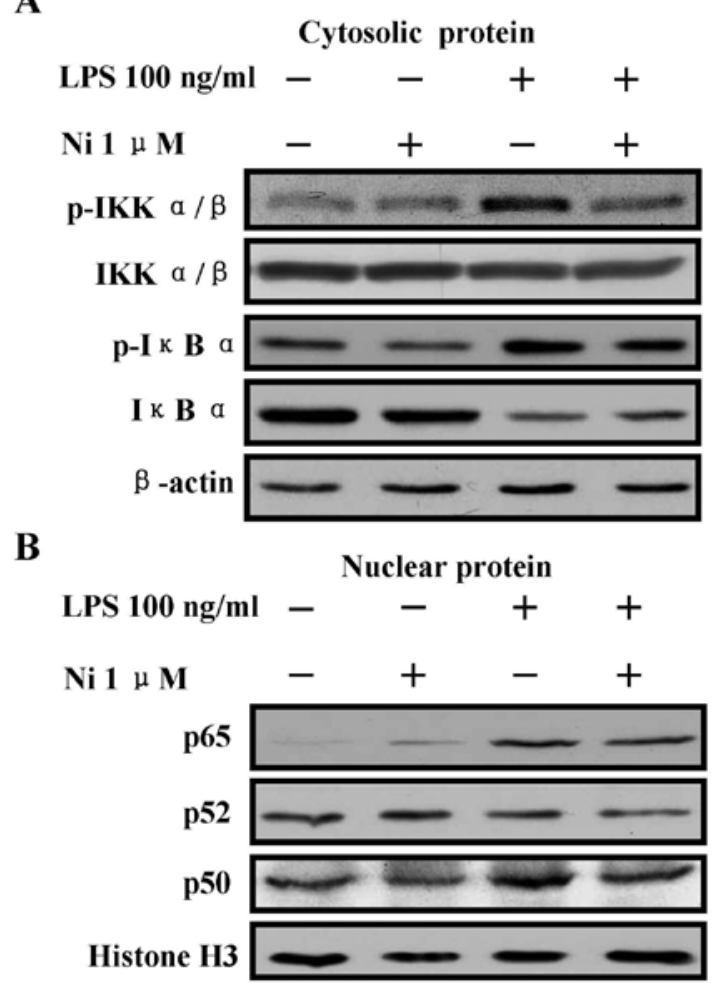

Figure 2. Nicotine inhibits LPS-induced NF-kB activation. Raw 264.7 cells were pretreated with $1 \mu \mathrm{M}$ nicotine $24 \mathrm{~h}$ prior to LPS $(100 \mathrm{ng} / \mathrm{ml})$ stimulation. Cytoplasmic and nuclear protein were extracted and the phosphorylation of IкB $\alpha, I K K \alpha / \beta$ in cytoplasm (A) and translocation of p65, p52, p50 to nucleus (B) were determined by western blotting. $\beta$-actin and histone $\mathrm{H} 3$ were used as cytoplasmic and nuclear protein loading control respectively. A representative out of three independent experiments is shown. $\mathrm{Ni}$, nicotine.

with the selective $\alpha 7 \mathrm{nAChR}$ antagonist $\alpha$-bungarotoxin. Interestingly, $\alpha$-bungarotoxin pre-incubation abolished the nicotine effect on TNF- $\alpha$ expression (Fig. 1D), indicating that the anti-inflammation effect of nicotine is $\alpha 7 \mathrm{nAChR}$ dependent.

The treatment with nicotine inhibits LPS-induced $N F-\kappa B$ activation. NF- $\mathrm{KB}$ pathway is crucial for pro-inflammatory cytokine production (24), which is regulated by $\mathrm{I} \kappa \mathrm{B} \alpha$ phosphorylation and degradation (25). LPS stimulation augmented the phosphorylation of IкB $\alpha$, IKK $\alpha / \beta$ in cytoplasm (Fig. $2 \mathrm{~A}$ ) and increased the translocation of $\mathrm{p} 65$ and $\mathrm{p} 50$ from cytosol to nucleus (Fig. 2B). The nicotine pretreatment abrogated the LPS effect on the phosphorylation of I $\mathrm{BB} \alpha, \mathrm{IKK} \alpha / \beta$ (Fig. 2A) and the translocation of p65 and p50 (Fig. 2B). These observations were consistent to the studies previously reported $(6,26)$. All these findings indicate that nicotine exhibits anti-inflammation effect by achieving NF- $\kappa$ B inactivation.

TIPE2 abrogates LPS-induced pro-inflammatory cytokine expression. TIPE2 overexpressed Raw 264.7 cells were established (Fig. 3A) and then the effect of TIPE2 on proinflammatory cytokine expression was determined. Without LPS stimulation, TIPE2 overexpression had no effect on proinflammatory cytokine secretion. Although LPS increased the expression of IL-1 $\beta$, IL-6, IL-2 and TNF- $\alpha$, TIPE2 overexpression abrogated the effect of LPS on these pro-inflammatory
A
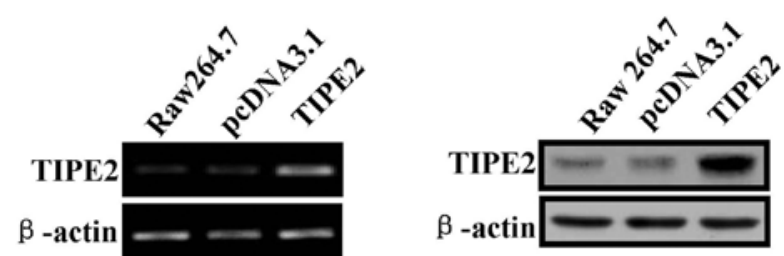

B
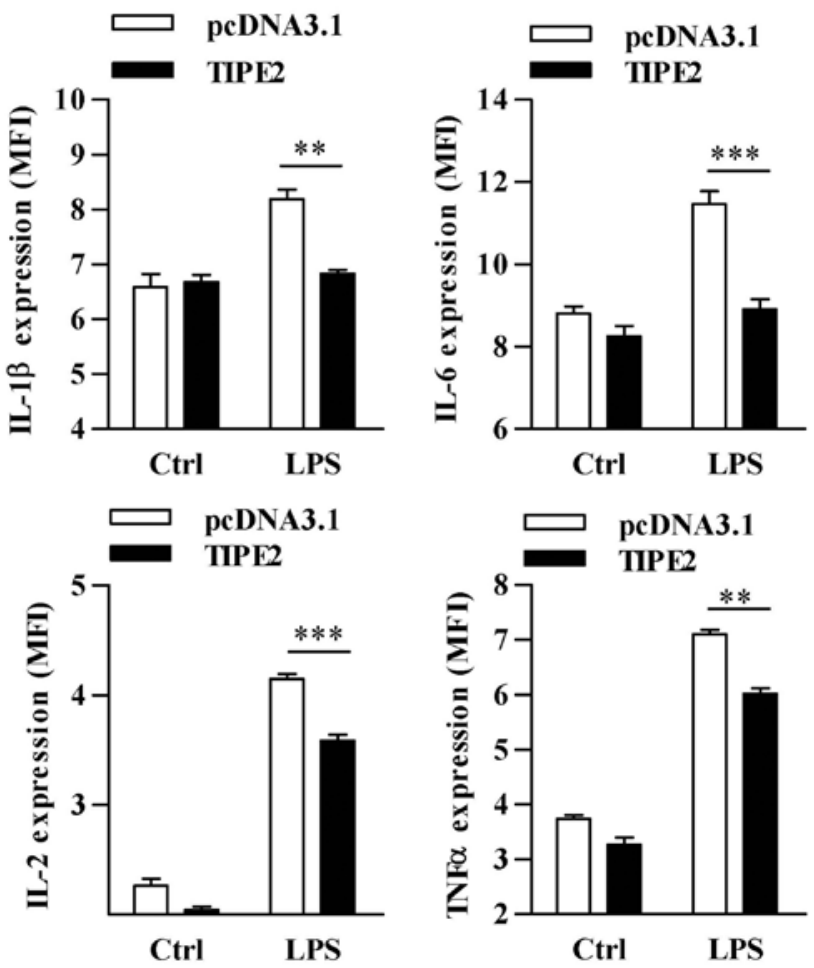

Figure 3. TIPE2 decreases LPS-induced pro-inflammatory cytokine secretion. TIPE2 was overexpressed in Raw 264.7 cells and confirmed by RT-PCR and western blotting (A) respectively. The cells were stimulated with $100 \mathrm{ng} / \mathrm{ml}$ LPS for $14 \mathrm{~h}$ and the expressions of IL-1 $\beta$, IL-2, IL-6 and TNF- $\alpha$ were determined by flow cytometry with intracellular staining (B). Data were given as mean \pm SEM. ${ }^{* *} \mathrm{p}<0.01,{ }^{* * *} \mathrm{p}<0.001$, Student's t-test. A representative of three independent experiments is shown.

cytokine release with the inhibitory rates of 16.5, 22.3, 13.6 and $15.2 \%$, respectively (Fig. 3B), indicating that TIPE2 is a negative regulator of inflammation.

TIPE2 abolishes LPS effect on $N F-\kappa B$ activation. TIPE2 overexpressed Raw 264.7 cells were treated with LPS and NF- $\kappa \mathrm{B}$ activation was investigated by western blotting. LPS stimulation enhanced IKK $\alpha / \beta$ and I $\mathrm{B} \alpha \alpha$ phosphorylation in the cytoplasm (Fig. 4A) and p65, p52, p50 translocation to the nucleus (Fig. 4B). TIPE2 overexpression inhibites LPS-induced phosphorylation of IKK $\alpha / \beta$ and I $\kappa \mathrm{B} \alpha$ in the cytoplasm (Fig.4A) and nuclear translocation of p65, p50 and p52 (Fig. 4B). These data indicate that TIPE2 inhibits pro-inflammatory cytokine release by achieving NF- $\mathrm{KB}$ inactivation.

$\alpha 7 n A c h R$ is involved in nicotine upregulated TIPE2 expression. Both nicotine and TIPE2 decrease LPS-induced inflammation by inhibiting NF- $\kappa \mathrm{B}$ activation. However, until now, little is known about the role of TIPE2 in nicotinemediated anti-inflammation effect. Nicotine administration increased TIPE2 transcription about 1.5- and 1.51-fold in 
A

Cytosolic protein

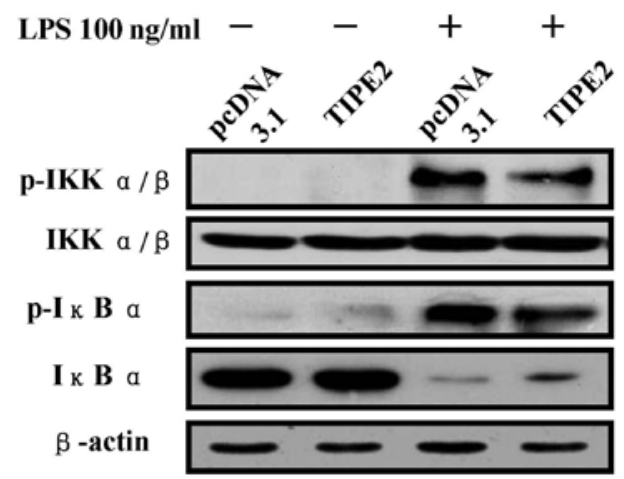

B

Nuclear protein

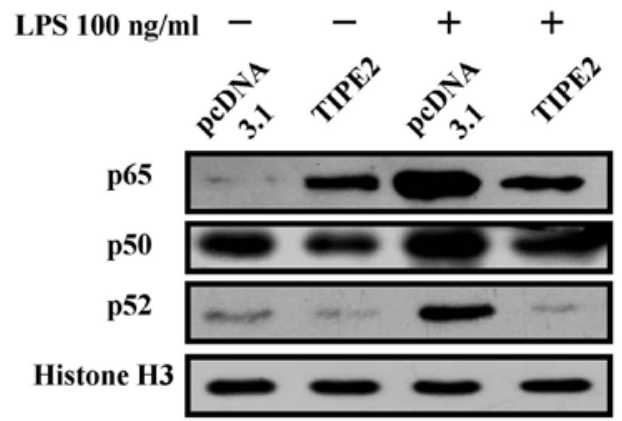

Figure 4. TIPE2 inhibits LPS-induced NF- $\kappa \mathrm{B}$ activation. TIPE2 overexpressed and control Raw 264.7 cells were treated with $100 \mathrm{ng} / \mathrm{ml}$ LPS Cytoplasmic and nuclear protein were extracted and the phosphorylation of $\mathrm{I} \kappa \mathrm{B} \alpha, \mathrm{IKK} \alpha / \beta$ in cytoplasm (A) and translocation of p65, p52, p50 to nucleus (B) were investigated by western blotting (A and B). $\beta$-actin and histone $\mathrm{H} 3$ were used as loading control. A representative out of three independent experiments is shown. spleen and thymus in vivo, respectively (Fig. 5A). The treatment with nicotine augmented TIPE2 expression in both macrophages and Raw 264.7 cells in vitro (Fig. 5B and C). To determine the role of $\alpha 7 \mathrm{nAChR}$ in nicotine-augmented TIPE2 expression, the cells were pre-incubated with $\alpha$-bungarotoxin prior to nicotine treatment. The treatment with nicotine increased TIPE2 expression, however, the pretreatment with $\alpha$-bungarotoxin abrogated the nicotine effect on TIPE2 upregulation (Fig. 5D). These results indicate that $\alpha 7 \mathrm{nAChR}$ is involved in nicotine-augmented TIPE2 expression.

Nicotine upregulates TIPE2 expression via Erk1/2 and $P I 3 K / A k t$ pathways. Although $\alpha 7 \mathrm{nAChR}$ is involved in nicotine-increased TIPE2 upregulation, the mechanism of nicotine-augmented TIPE2 expression is still unclear. To address this issue, PD98059, U0126, LY294002 and Wortmannin were used prior to nicotine stimulation and TIPE2 expression was determined. Consistent with our previous report (20), nicotine rapidly increase the phosphorylation of PI3K/Akt and Erk1/2, from 5 to $120 \mathrm{~min}$ (Fig. 6A). As these inhibitors efficiently inhibited the related kinase activities, the pretreatments of U0126, PD98059, LY294002 and Wortmannin abrogating the effect of nicotine on TIPE2 upregulation (Fig. 6B), indicate that nicotine-augmented TIPE2 expression via Erk1/2 and PI3K/Akt pathways.

Nicotine-increased stat3 phosphorylation contributes to the inhibition of p65 translocation. Nicotine increases stat 3 phosphorylation and suppress inflammatory cytokines production $(16,27)$, indicating that stat 3 might be a negative regulator of inflammation. To explore the effect of stat 3 phosphorylation
A

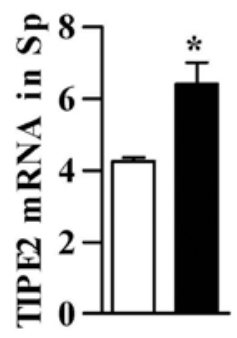

Ctrl Ni

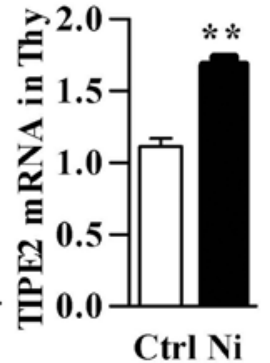

Ctrl Ni

C

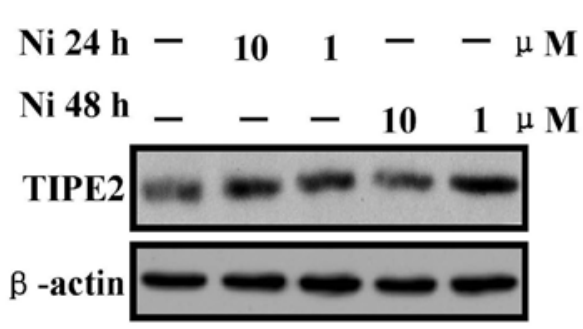

B

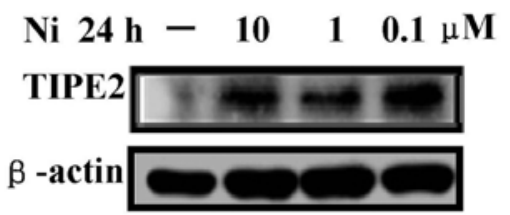

D

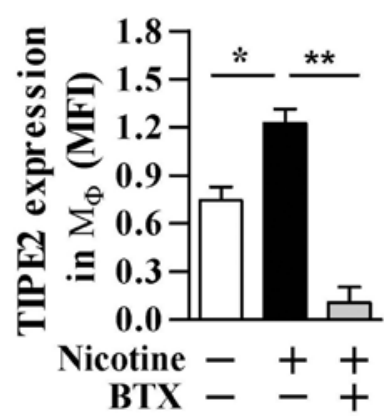

Figure 5. $\alpha 7 \mathrm{nAchR}$ is involved in nicotine-increased TIPE2 expression. Balb/c mice (A), murine bone marrow-derived macrophage (B) and Raw 264.7 cells (C) were treated with nicotine. TIPE2 expression in spleen/thymus (A), macrophage (B) and Raw 264.7 cells (C) was determined by real-time PCR and western blotting, respectively. For in vivo animal test, mice were subcutaneously injected with nicotine $(0.5 \mu \mathrm{g} / 10 \mathrm{~g}$, twice per day) for 9 days. Murine macrophage was pretreated with $1 \mu \mathrm{g} / \mathrm{ml} \alpha$-bungarotoxin prior to $1 \mu \mathrm{M}$ nicotine stimulation and the expression of TIPE2 was determined by flow cytometry (D). Data are given as mean \pm SEM, $n=3,{ }^{*} p<0.05,{ }^{* *} \mathrm{p}<0.01$, Student's t-test or one-way ANOVA with post Newman-Keuls test. A representative out of three independent experiments is shown. $\mathrm{Ni}$, nicotine; BTX, $\alpha$-bungarotoxin. 
A

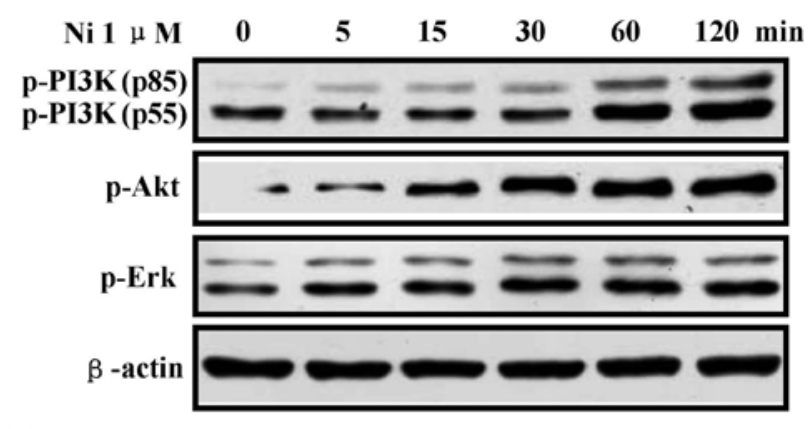

B

\begin{tabular}{|c|c|c|c|c|c|c|}
\hline DMSO & + & - & - & - & - & - \\
\hline $\mathbf{N i} 1 \mu \mathrm{M}$ & - & + & + & + & + & + \\
\hline PD98059 & - & - & + & - & - & - \\
\hline U0126 & - & - & - & + & - & - \\
\hline LY294002 & - & - & - & - & + & - \\
\hline Wortmannin & & - & - & - & - & + \\
\hline TIPE2 & - & & $=$ & $=$ & $=$ & = \\
\hline p-Erk & & & - & & $=$ & \\
\hline & & & & & - & \\
\hline$\beta$-actin & & & & & & \\
\hline
\end{tabular}

Figure 6. Nicotine upregulates TIPE2 expression via Erk1/2 and PI3K/Akt pathways. Raw 264.7 cells were treated with $1 \mu \mathrm{M}$ nicotine for indicated periods and the phosphorylation of Erk1/2 and PI3K/Akt was determined by western blotting (A). Raw 264.7 cells were pretreated with PD98059, U0126, LY294002 or Wortmannin prior to nicotine stimulation and the expression of TIPE2 was determined by western blotting (B). A representative out of three independent experiments is shown. $\beta$-actin was used as loading control. $\mathrm{Ni}$, nicotine. on p65 translocation, Raw 264.7 cells were pretreated with AG490 prior to nicotine stimulation. p65 translocation and stat 3 phosphorylation were investigated by western blotting. As upstream kinase of stat3, Jak2 phosphorylation was increased by the treatment with nicotine from 5 to $120 \mathrm{~min}$ (Fig. 7A). Stat3 phosphorylation was also achieved by the treatment with nicotine from 60 min to $24 \mathrm{~h}$ (Fig. 7A and B). In contrast to decreased levels of p65 and phosphorylated stat 3 in the cytosol (Fig. 7C), LPS treatment increased the levels of p65 and phosphorylated stat 3 in the nucleus (Fig. 7D), indicating that LPS enhance nuclear translocation of p65 and phosphorylated stat3. Compared with LPS-treated cells, the pretreatment with nicotine increased the levels of p65 and phosphorylated stat3 in cytosol (Fig. 7C) and decreased the levels of p65 and phosphorylated stat 3 in the nucleus (Fig. 7D). Importantly, when AG490 was added to inhibit stat3 activities, the decreased p65 in cytosol and increased p65 in nucleus were also achieved (Fig. 7C and D). These data indicate that the phosphorylation of stat 3 plays a potential role in nicotinemediated NF- $\kappa \mathrm{B}$ inactivation.

Nicotine augments the interaction of phosphorylated stat 3 and $p 65$. Stat 3 inhibited inducible NO synthase expression in mesangial cells by interacting with $N F-\kappa B(28)$. Due to the observation that the pretreatment with nicotine enhanced stat 3 phosphorylation and inhibited LPS-induced p65 translocation, we speculated that the inhibitory effect of nicotine on $\mathrm{NF}-\kappa \mathrm{B}$ activation might be due to the increased interaction of phosphorylated stat 3 and p65. In Fig. 8A, while LPS treatment had no effect on the interaction of phosphorylated stat 3 and p65, nicotine pretreatment achieved an obvious band of phosphorylated stat3 (Fig. 8A). As LPS treatment increased stat3 phosphorylation from 4 to $6 \mathrm{~h}$ in Raw264.7 cells (29), it is no surprise to find that phosphorylated stat 3 can not be detected

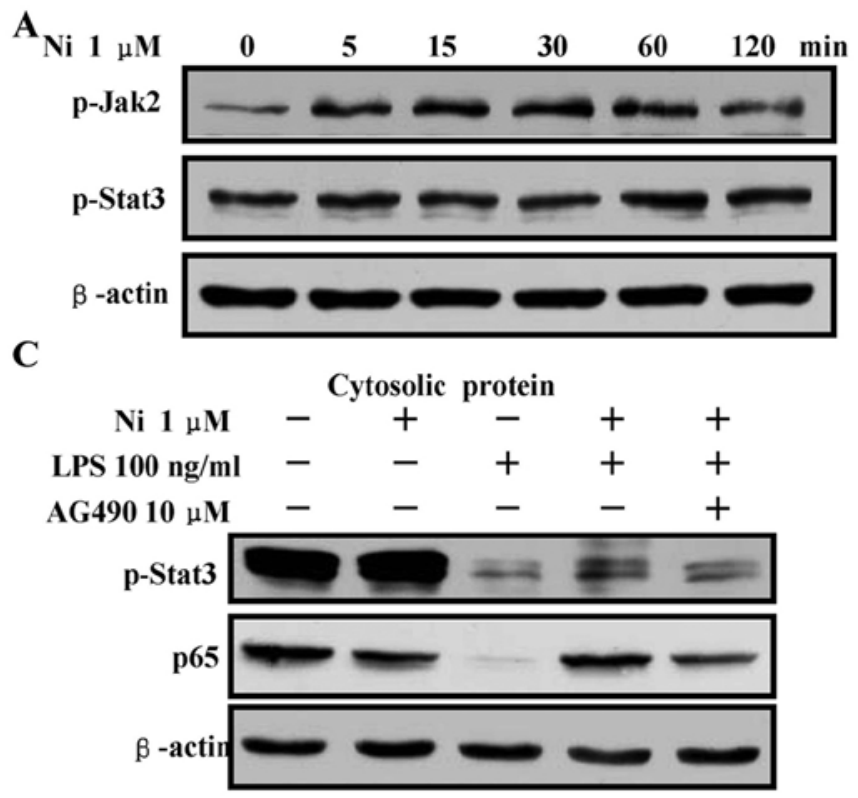

B

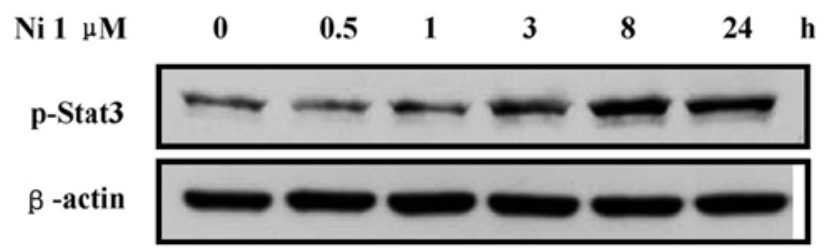

D

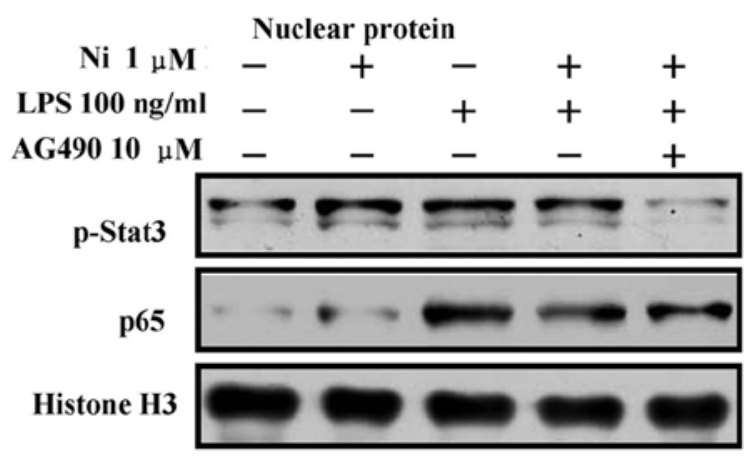

Figure 7. Nicotine-increased stat 3 phosphorylation inhibits LPS-induced p 65 translocation. Raw 264.7 cells were treated with $1 \mu \mathrm{M}$ nicotine and stat 3 phosphorylation was determined by western blotting (A and B). Then, Raw 264.7 cells pretreated with AG490 (10 $\mu \mathrm{M})$ prior to 24-h nicotine stimulation were further conferred $100 \mathrm{ng} / \mathrm{ml}$ LPS treatment. p65 translocation and Stat3 phosphorylation were determined by western blotting (C and D) respectively. $\beta$-actin and histone $\mathrm{H} 3$ were used as loading control. A representative out of three independent experiments is shown. Ni, nicotine. 
A

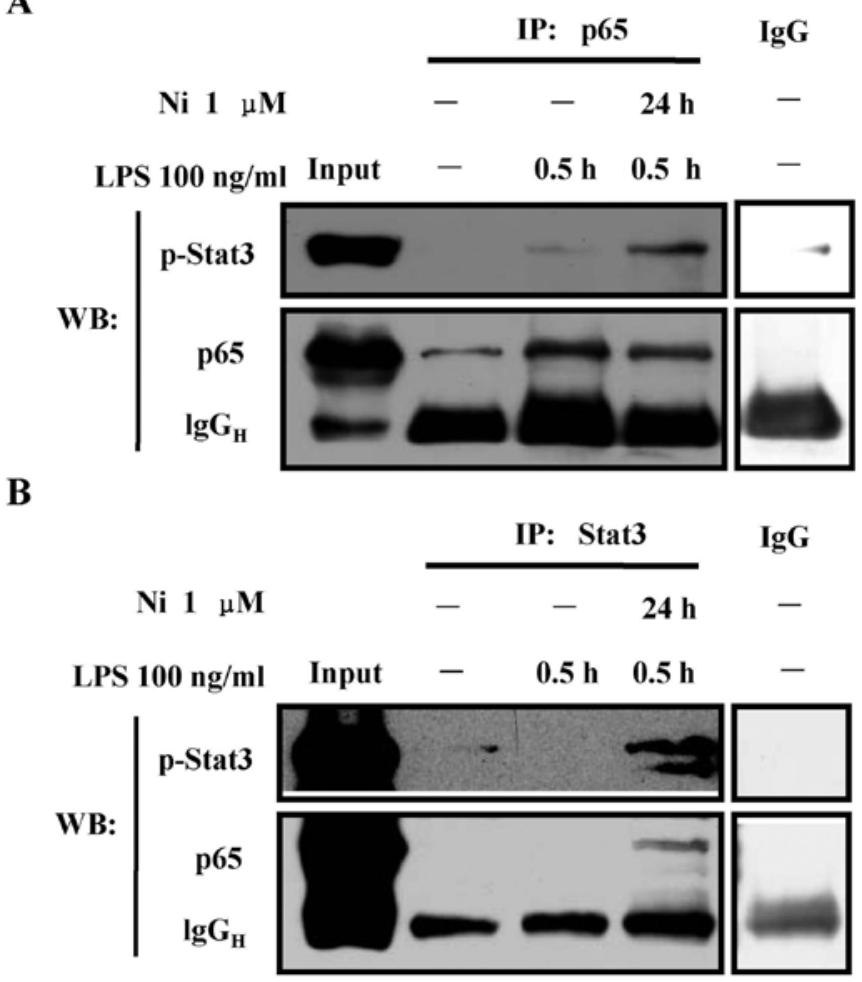

Figure 8. Nicotine augments the interaction of phosphorylated stat 3 and p65. Raw 264.7 cells pretreated with $1 \mu \mathrm{M}$ nicotine prior to $100 \mathrm{ng} / \mathrm{ml}$ LPS stimulation. Immunoprecipitated (IP) was performed using monoclonal p65 (A) or Tyr705-phosphorylated stat3 (B) antibodies. Anti-mouse IgG or anti-rabbit IgG was used as negative controls. Whole cellular protein was used as input control. $\mathrm{IgG}_{\mathrm{H}}$ represents immunoglobulin heavy chain. A representative out of three independent experiments was shown. $\mathrm{Ni}$, nicotine.

in short-term LPS-stimulated cells (30 min) when total stat3 antibody was applied to perform co-immunoprecipitation assay (Fig. 8B). Importantly, despite the level of control heavy chain in nicotine-pretreated cells was slight higher, the obvious bands of $\mathrm{p} 65$ and phosphorylated stat 3 revealed an interaction of phosphorylated stat 3 and p65 (Fig. 8B). These observations indicate that the inhibitory effect of nicotine on NF- $\kappa \mathrm{B}$ activation is mediated by the interaction of phosphorylated stat 3 and $\mathrm{p} 65$.

\section{Discussion}

Inflammation contribute to systemic capillary leakage syndrome, tissue injury and fatal organ failure $(1,2)$. Cholinergic agonist was useful for control of depression, Tourette's syndrome, Parkinson's disease, Crohn's disease and ulcerative colitis (9-11), indicating that $\alpha 7 \mathrm{nAChR}$ is crucial for inflammation regulation (30). Preserving cytoplasmic levels of inhibitor of $\mathrm{NF}-\kappa \mathrm{B}(\mathrm{I} \kappa \mathrm{B})$ was found to be essential for nicotine-mediated $N F-\kappa B$ inhibition $(5,6)$. Whereas, Jak2/stat3 signaling was also documented to facilitate nicotine's anti-inflammation effect (16). Hence, the exact role of stat 3 in nicotine-mediated cholinergic $N F-\kappa B$ inhibition is still uncertain. In this study, we demonstrated that nicotine exerts its anti-inflammatory effect by TIPE2 upregulation and augmented interaction of phosphorylated stat 3 and p65. All these observations indicate that TIPE2 and stat 3 might be potential molecules for dealing with inflammation-associated diseases.

TIPE2 inhibits TCR-mediated $\mathrm{T}$ cell activation and maintain immune homeostasis (17). In this study, TIPE2 upregulation via Erk1/2 and PI3K/Akt pathways was found to contribute to nicotine-mediated $\mathrm{NF}-\kappa \mathrm{B}$ inhibition. PI3K/Akt/ mTOR pathway mediated nicotine-induced tumor growth and chemoresistance in bladder cancer (31). Other studies also demonstrated that co-stimulator molecules on dendritic cell can be up-rgulated by nicotine via Erk1/2 and PI3K/Akt pathway (20,32). As PI3K and AKT regulated the epigenetic regulator KMT2D and histone methyltransferase WHSC1 respectively $(33,34)$, PI3K/AKT-mediated epigenetic regulation might contribute to nicotine affecting TIPE2 expression. As p38/JNK MAPK and stat3 pathways were also activated by nicotine treatment (Fig. 7) (20). Further studies are needed to explore epigenetic regulation of these kinases in nicotineaugmented TIPE2 expression.

Cell viability assay showed that lower doses of nicotine had no effect on dendritic cell apoptosis, but higher doses of nicotine actually induced $>90 \%$ cell programming into the process of apoptosis, indicating that nicotine is somehow toxic to cell viability (35). Short-term exposure to nicotine enhanced lymphocyte c-fos gene expression, but long-term exposure downregulated $n A c h R$ mRNA expression (36). In our experiments, nicotine had a maximal effect at $0.1 \mu \mathrm{M}$ concentration on TIPE2 upregulation, which can also be found in other reports (32). This controversy regarding the effects of nicotine on TIPE2 expression may be attributed to nicotine concentration used in the experiments.

$\mathrm{NF}-\kappa \mathrm{B}$ pathway, which is regulated by $\mathrm{I} \kappa \mathrm{B} \alpha$ phosphorylation and degradation (25), is crucial for pro-inflammatory cytokine expression (24). In this study, TIPE2 was found to inhibit pro-inflammatory cytokine release (Fig. 3) and induce $\mathrm{NF}-\kappa \mathrm{B}$ inactivation (Fig. 4). Interestingly, TNF- $\alpha$ induced protein 3 (TNFAIP3, A20), has similar effect as TIPE2 on $\mathrm{NF}-\kappa \mathrm{B}$ pathway activation (37). N-terminal of A20 encodes a deubiquitinating (DUB) domain which mediates the deubiquitination of K63-polyubiquitinated NF- $\mathrm{NB}$ signaling proteins such as TRAF6 and RIP1, while the C-terminal of A20 encodes seven zinc-finger (ZF) motifs and confers E3 ubiquitin ligase activity (38). The report that A20 binding to unanchored K63-linked polyubiquitin chains and NEMO to block IKK's upstream kinase TAK1 (39) indicated that a direct non-catalytic mechanism of A20 inhibit NF- $\kappa$ B activities. As both TIPE2 and A20 have negative regulation effects on immune function and NF- $\kappa \mathrm{B}$ activation, whether TIPE2 had deubiquitinase enzyme domains and TIPE2 antagonized the ubiquitination of NEMO-IкB kinase complex (IKK) regulatory subunit by the interaction with NEMO need further exploration.

Stat3, which is critical for cell differentiation, growth, apoptosis, innate and adaptive immunity (13), can be activated by $\mathrm{nAChR}$ ligation and regulated pro-inflammatory cytokine release (27). In this study, the phosphorylation of stat3 was augmented by the treatment with nicotine (Fig. 7). Further investigations revealed that stat 3 phosphorylation prevented nuclear translocation of p65 (Fig. 7). Stat3 inhibited inducible nitric oxide synthase transcription by interacting with NF- $\mathrm{B}$ (28). Hence, it is not surprising to find that the 
pretreatment of AG490 partially restored the effect of LPS on $\mathrm{p} 65$ translocation. Importantly, the treatment with nicotine augmented the interaction of $\mathrm{p} 65$ and phosphorylated stat3 (Fig. 8), indicating that the inhibitory effect of nicotine on $\mathrm{NF}-\mathrm{KB}$ activation was mediated by the interaction of phosphorylated stat 3 and $\mathrm{p} 65$.

Taken together, our studies revealed that the anti-inflammation effect of nicotine might be due to TIPE2 upregulation and stat 3 phosphorylation, providing that TIPE2 and stat 3 might be potential molecules for dealing with inflammationassociated diseases.

\section{Acknowledgements}

We thank Professor Y.H. Chen (University of Pennsylvania, USA) for kindly providing TIPE2 plasmid and valuable advice. Also, we thank Jin Hua Su and Fu Chen for excellent animal care. This study was supported by grants from the State Key Laboratory of Oncogenes and Related Genes (no. 90-14-05) and by grants from the National Natural Science Foundation of China (no. 81273203).

\section{References}

1. Matteoli G, Gomez-Pinilla PJ, Nemethova A, Di Giovangiulio M, Cailotto C, van Bree SH, Michel K, Tracey KJ, Schemann M, Boesmans W, et al: A distinct vagal anti-inflammatory pathway modulates intestinal muscularis resident macrophages independent of the spleen. Gut 63: 938-948, 2014.

2. Martelli D, McKinley MJ and McAllen RM: The cholinergic antiinflammatory pathway: A critical review. Auton Neurosci 182: 65-69, 2014.

3. Bonaz B, Sinniger V and Pellissier S: Anti-inflammatory properties of the vagus nerve: Potential therapeutic implications of vagus nerve stimulation. J Physiol 594: 5781-5790, 2016.

4. Han B, Li X and Hao J: The cholinergic anti-inflammatory pathway: An innovative treatment strategy for neurological diseases. Neurosci Biobehav Rev 77: 358-368, 2017.

5. Guarini S, Altavilla D, Cainazzo MM, Giuliani D, Bigiani A, Marini H, Squadrito G, Minutoli L, Bertolini A, Marini R, et al: Efferent vagal fibre stimulation blunts nuclear factor-kappaB activation and protects against hypovolemic hemorrhagic shock. Circulation 107: 1189-1194, 2003.

6. Saeed RW, Varma S, Peng-Nemeroff T, Sherry B, Balakhaneh D, Huston J, Tracey KJ, Al-Abed Y and Metz CN: Cholinergic stimulation blocks endothelial cell activation and leukocyte recruitment during inflammation. J Exp Med 201: 1113-1123, 2005.

7. Karin M and Greten FR: NF-kappaB: Linking inflammation and immunity to cancer development and progression. Nat Rev Immunol 5: 749-759, 2005.

8. Lin Y, Bai L, Chen W and Xu S: The NF-kappaB activation pathways, emerging molecular targets for cancer prevention and therapy. Expert Opin Ther Targets 14: 45-55, 2010.

9. Avila J and Díaz-Nido J: Tangling with hypothermia. Nat Med 10: 460-461, 2004

10. Dong J, Segawa R, Mizuno N, Hiratsuka M and Hirasawa N: Inhibitory effects of nicotine derived from cigarette smoke on thymic stromal lymphopoietin production in epidermal keratinocytes. Cell Immunol 302: 19-25, 2016.

11. Libert C: Inflammation: A nervous connection. Nature 421: 328-329, 2003.

12. Jie Z, Dinwiddie DL, Senft AP and Harrod KS: Regulation of STAT signaling in mouse bone marrow derived dendritic cells by respiratory syncytial virus. Virus Res 156: 127-133, 2011.

13. Subramaniam A, Shanmugam MK, Perumal E, Li F, Nachiyappan A, Dai X, Swamy SN, Ahn KS, Kumar AP, Tan BK, et al: Potential role of signal transducer and activator of transcription (STAT)3 signaling pathway in inflammation, survival, proliferation and invasion of hepatocellular carcinoma. Biochim Biophys Acta 1835: 46-60, 2013.
14. Takeda K, Clausen BE, Kaisho T, Tsujimura T, Terada N, Förster I and Akira S: Enhanced Th1 activity and development of chronic enterocolitis in mice devoid of Stat 3 in macrophages and neutrophils. Immunity 10: 39-49, 1999.

15. Welte T, Zhang SS, Wang T, Zhang Z, Hesslein DG, Yin Z, Kano A, Iwamoto Y, Li E, Craft JE, et al: STAT3 deletion during hematopoiesis causes Crohn's disease-like pathogenesis and lethality: A critical role of STAT3 in innate immunity. Proc Natl Acad Sci USA 100: 1879-1884, 2003.

16. de Jonge WJ, van der Zanden EP, The FO, Bijlsma MF, van Westerloo DJ, Bennink RJ, Berthoud HR, Uematsu S, Akira S, van den Wijngaard RM, et al: Stimulation of the vagus nerve attenuates macrophage activation by activating the Jak2-STAT3 signaling pathway. Nat Immunol 6: 844-851, 2005.

17. Sun H, Gong S, Carmody RJ, Hilliard A, Li L, Sun J, Kong L, $\mathrm{Xu} \mathrm{L}$, Hilliard $\mathrm{B}, \mathrm{Hu} \mathrm{S}$, et al: TIPE2, a negative regulator of innate and adaptive immunity that maintains immune homeostasis. Cell 133: 415-426, 2008.

18. Zhang Y, Wei X, Liu L, Liu S, Wang Z, Zhang B, Fan B, Yang F, Huang S, Jiang F, et al: TIPE2, a novel regulator of immunity, protects against experimental stroke. J Biol Chem 287: 32546-32555, 2012.

19. Gao FG, Wan F and Gu JR: Ex vivo nicotine stimulation augments the efficacy of therapeutic bone marrow-derived dendritic cell vaccination. Clin Cancer Res 13: 3706-3712, 2007.

20. Jin HJ, Sui HX, Wang YN and Gao FG: Nicotine up-regulated 4-1BBL expression by activating Mek-PI3K pathway augments the efficacy of bone marrow-derived dendritic cell vaccination. J Clin Immunol 33: 246-254, 2013.

21. Ke SZ, Ni XY, Zhang YH, Wang YN, Wu B and Gao FG: Camptothecin and cisplatin upregulate ABCG2 and MRP2 expression by activating the ATM/NF- $\kappa \mathrm{B}$ pathway in lung cancer cells. Int J Oncol 42: 1289-1296, 2013.

22. Jin HJ, Li HT, Sui HX, Xue MQ, Wang YN, Wang JX and Gao FG: Nicotine stimulated bone marrow-derived dendritic cells could augment HBV specific CTL priming by activating PI3K-Akt pathway. Immunol Lett 146: 40-49, 2012.

23. Lu ZG, Liu H, Yamaguchi T, Miki Y and Yoshida K: Protein kinase Cdelta activates RelA/p65 and nuclear factor-kappaB signaling in response to tumor necrosis factor-alpha. Cancer Res 69: 5927-5935, 2009.

24. Nyati KK, Masuda K, Zaman MM, Dubey PK, Millrine D, Chalise JP, Higa M, Li S, Standley DM, Saito K, et al: TLR4-induced NF- $\kappa$ B and MAPK signaling regulate the IL-6 mRNA stabilizing protein Arid5a. Nucleic Acids Res 45: 2687-2703, 2017.

25. Buhrmann C, Mobasheri A, Busch F, Aldinger C, Stahlmann R, Montaseri A and Shakibaei M: Curcumin modulates nuclear factor kappaB (NF-kappaB)-mediated inflammation in human tenocytes in vitro: Role of the phosphatidylinositol 3-kinase/Akt pathway. J Biol Chem 286: 28556-28566, 2011.

26. Wang $H$, Liao $H$, Ochani $M$, Justiniani $M$, Lin $X$, Yang L, Al-Abed Y, Wang H, Metz C, Miller EJ, et al: Cholinergic agonists inhibit HMGB1 release and improve survival in experimental sepsis. Nat Med 10: 1216-1221, 2004.

27. Wang T, Niu G, Kortylewski M, Burdelya L, Shain K, Zhang S, Bhattacharya R, Gabrilovich D, Heller R, Coppola D, et al: Regulation of the innate and adaptive immune responses by Stat-3 signaling in tumor cells. Nat Med 10: 48-54, 2004.

28. Yu Z, Zhang W and Kone BC: Signal transducers and activators of transcription 3 (STAT3) inhibits transcription of the inducible nitric oxide synthase gene by interacting with nuclear factor kappaB. Biochem J 367: 97-105, 2002.

29. Lee SB, Lee WS, Shin JS, Jang DS and Lee KT: Xanthotoxin suppresses LPS-induced expression of iNOS, COX-2, TNF- $\alpha$, and IL-6 via AP-1, NF- $\kappa$ B, and JAK-STAT inactivation in RAW 264.7 macrophages. Int Immunopharmacol 49: 21-29, 2017.

30. Pavlov VA and Tracey KJ: The vagus nerve and the inflammatory reflex - linking immunity and metabolism. Nat Rev Endocrinol 8: 743-754, 2012.

31. Yuge K, Kikuchi E, Hagiwara M, Yasumizu Y, Tanaka N, Kosaka T, Miyajima A and Oya M: Nicotine induces tumor growth and chemoresistance through activation of the PI3K/ Akt/mTOR pathway in bladder cancer. Mol Cancer Ther 14: 2112-2120, 2015.

32. Aicher A, Heeschen C, Mohaupt M, Cooke JP, Zeiher AM and Dimmeler S: Nicotine strongly activates dendritic cell-mediated adaptive immunity: Potential role for progression of atherosclerotic lesions. Circulation 107: 604-611, 2003. 
33. Toska E, Osmanbeyoglu HU, Castel P, Chan C, Hendrickson RC, Elkabets M, Dickler MN, Scaltriti M, Leslie CS, Armstrong SA, et al: PI3K pathway regulates ER-dependent transcription in breast cancer through the epigenetic regulator KMT2D. Science 355: 1324-1330, 2017.

34. Li N, Xue W, Yuan H, Dong B, Ding Y, Liu Y, Jiang M, Kan S, Sun T, Ren J, et al: AKT-mediated stabilization of histone methyltransferase WHSC1 promotes prostate cancer metastasis. J Clin Invest 127: 1284-1302, 2017.

35. Hu SX, Sui HX, Jin HJ, Ni XY, Liu XX, Xue MQ, Zhang Y and Gao FG: Lipopolysaccharide and dose of nicotine determine the effects of nicotine on murine bone marrow-derived dendritic cells. Mol Med Rep 5: 1005-1010, 2012.

36. Kawashima K and Fujii T: The lymphocytic cholinergic system and its contribution to the regulation of immune activity. Life Sci 74: 675-696, 2003.
37. Dixit VM, Green S, Sarma V, Holzman LB, Wolf FW, O'Rourke K, Ward PA, Prochownik EV and Marks RM: Tumor necrosis factor-alpha induction of novel gene products in human endothelial cells including a macrophage-specific chemotaxin. J Biol Chem 265: 2973-2978, 1990.

38. Wertz IE, O'Rourke KM,Zhou H, Eby M, Aravind L, Seshagiri S, Wu P, Wiesmann C, Baker R, Boone DL, et al: De-ubiquitination and ubiquitin ligase domains of A20 downregulate NF-kappaB signalling. Nature 430: 694-699, 2004.

39. Skaug B, Chen J, Du F, He J, Ma A and Chen ZJ: Direct, noncatalytic mechanism of IKK inhibition by A20. Mol Cell 44: 559-571, 2011. 